Table 2. Amounts of urine excreted by rats given by stomach tube $5 \mathrm{ml}$. water/100 $\mathrm{g}$ body-weight. Each figure is the mean volume of urine in $m l$. excreted by four rats

\begin{tabular}{lccccc}
\multicolumn{1}{c}{ Drug } & \multicolumn{4}{c}{ Volume } & Mean \\
Nicotine with hexamethonium & $35 \cdot 9$ & $42 \cdot \mathrm{I}$ & $44 \cdot 6$ & $42 \cdot 2$ & $4 \mathrm{I} \cdot 2$ \\
Nicotine alone & $38 \cdot \mathrm{I}$ & $39 \cdot 4$ & $47 \cdot 7$ & & $4 \mathrm{I} \cdot 7$ \\
Hexamethonium alone & $33 \cdot 2$ & $29 \cdot 9$ & $38 \cdot 6$ & & $33 \cdot 9$ \\
No drug & $30 \cdot \mathrm{I}$ & $33 \cdot \mathrm{I}$ & & & $3 \mathrm{I} \cdot 6$
\end{tabular}

between the groups receiving nicotine and hexamethonium and those receiving nicotine alone. But the mean volumes excreted by rats receiving nicotine are much greater than those of the groups receiving none. We do not yet know how this diuresis is brought about, nor whether it has any significance for smokers. The amounts of nicotine given to the rats $\left(0.5^{-1} \cdot 0 \mathrm{mg}\right.$ nicotine acid tartrate per 100 $\mathrm{g}$ body-weight) were relatively enormous compared with what would be absorbed by a man who smoked, and I know of no evidence that smoking ever causes a diuresis.

We have considered two aspects of the physiological effects of smoking. The effect on body-weight is of practical importance but not clearly understood; that on water metabolism is clearly established experimentally, but of doubtful significance.

\title{
REFERENCES
}

Burn, J. H. (195 I). Brit. med. F. ii, 199.

Carlson, A. J. \& Lewis, J. H. (1914). Amer. F. Physiol. 34, I49.

Dill, D. B., Edwards, H. T. \& Forbes, W. H. (1934). Amer. F. Physiol. rog, 118.

Grossman, M. I. \& Cummins, G. M. (1947). Quoted by Harris, S. C., Ivy, A. C. \& Searle, L. M. ( 1947). F. Amer. med. Ass. 134, 1468.

Grossman, M. I., Cummins, G. M. \& Ivy, A. C. (1947). Amer. F. Physiol. 149, 100.

Haggard, H. W. \& Greenberg, L. A. (1934). Science, 79, 165.

Koehler, A. E., Hill, E. \& Marsh, N. (1947). Gastroenterology, 8, 208.

Lundberg, E. \& Thyselius-Lundberg, S. (I93 I). Acta med. scand. Suppl. 38.

Quigley, J. P. \& Hallaran, W. R. (193 I). Amer. F. Physiol. 97, 552.

Quigley, J. P. \& Hallaran, W. R. (1932). Amer. F. Physiol. 1oo, 102.

Sangster, W., Grossman, M. I. \& Ivy, A. C. (1948). Amer. F. Physiol. 153, 259.

Schnedorf, J. G. \& Ivy, A. C. (1939), Э. Amer. med. Ass. I12, 898.

Short, J. J. \& Johnson, H. T. (1939). F. Lab. clin. Med. 24, 590.

Wacholder, K. (1948). Arch. exp. Path. Pharmak. 205, II 5.

Williams, R. H., Doughaday, W. H., Rogers, W. F., Asper, S. P. \& Towery, B. Y. (1948). Ann. intern. Med. 29, $5 \mathrm{IO}$.

\section{The Effect of Lesions in the Hypothalamus on Appetite}

\author{
By G. C. KENNEDY, Clinical Endocrinology Research Unit, \\ Royal Infirmary, Edinburgh
}

In the light of knowledge acquired in the last few years, it now seems natural to think of the hypothalamus and the pituitary as almost inseparable parts of functional unit. The pituitary is anatomically conspicuous, its main structural features being obvious even to the naked eye; the structure of the hypothalamus remains something of a mystery in spite of present-day microscopical techniques. The pituitary 
has interested physicians ever since Vesalius named it in the sixteenth century, under the mistaken impression that it secreted the nasal mucus or pituita. Our modern concept of its function can be said to date from the observation of Pierre Marie that one type of tumour of the gland caused acromegaly. Marie's conclusion that, because destruction of the gland caused increased growth, the normal function must be to hold growth in check, we now know to be the precise opposite of the truth. All the same, he did establish the association of the gland with growth. It was just such masterly errors by the great clinicians of his day, whose names are now the eponyms of endocrine disease, that led to our concept of internal secretion.

Fifteen years after Marie's paper, Alfred Fröhlich noticed that tumours of the pituitary region often failed to produce acromegaly, but produced instead a combination of obesity and sexual infantilism, which subsequently became known as Fröhlich's syndrome or dystrophia adiposo-genitalis. Fröhlich, like Marie, attributed the symptoms he described to diminished function of the pituitary. In this he was wrong, but the wrong was set right 3 years later, in 1904, by another great Viennese, Erdheim, who pointed out that the syndrome was often associated with tumours that damaged the brain rather then the gland. He wrote 'We agree with Fröhlich that pathological obesity is of frequent occurrence in hypophyseal tumours. It seems to us, however, that he is unjustified in his interpretation that a change of function of the hypophysis as an endocrine gland is responsible for the adiposity. We further believe that the reason for it must be sought in the tumour's influence-be it injury or stimulation-on the region of the base of the brain'. Modern physiology has supported Erdheim's view, and Fröhlich eventually came to agree with him, yet there are still those who cling to a belief in the endocrine basis of obesity. The mistakes of later endocrinologists should not blind us to the greatness of these early Viennese, to whose clinical picture the last 50 years has added little. The best tribute to them is the constant rediscovery of the disease they described.

The crucial experiment demonstrating that the hypothalamus could be damaged in such a way as to cause gross obesity, without any suspicion of damage to the pituitary, did not occur until 4o years after the Erdheim-Fröhlich controversy. Earlier experiments, of which there were many, were inconclusive, because the hypothalamus was always approached from below, so that the pituitary also was almost inevitably damaged. But Hetherington \& Ranson (1939) and later Brobeck, Tepperman \& Long (1943) showed that the hypothalamus could be damaged by an electrode introduced from above without any harm to the pituitary. The technique had been described by Sir Victor Horsely many years before, and it is surprising that it was so long before it was applied to the study of the hypothalamus. This and previous experimental work has been thoroughly reviewed by Brobeck (1946). Suffice it to say that there is now no reasonable doubt that the cause of the obesity often associated with damage to structures in the pituitary region lies in the hypothalamus and not in the gland itself. So much emerged from the work of Ranson's group, but the exact region of the hypothalamus responsible was not defined, and it was not clear whether the immediate cause of the obesity lay in an 
increase of food intake or a decrease in activity. Brobeck cleared up both these points by showing that by far the most important factor was an increase in food intake, and that bilateral lesions in the region of the ventro-medial nuclei of the hypothalamus were necessary. The original work was done on the rat, but confirmatory studies have been done on the cat, the dog and the monkey, and it is a reasonable assumption from clinical evidence that a similar mechanism operates in man. The period of increased food intake or hyperphagia, as Brobeck has called it, is followed by a return to approximately normal food intake and rate of growth when the obesity is maximal. At any stage after the development of the obesity, the rat can be reduced to the same weight as its control by starvation; if it is then given free access to food again, the whole picture of hyperphagia is reproduced and the animal again reaches about the same degree of obesity. This varies from rat to rat and appears to be a function of the degree of damage to the responsible hypothalamic neurons. It is perhaps of some interest that determination of the fat content of the most obese rats on record shows the fraction of their body formed by fat to be almost identical with that in very fat women as well as in fat pigs (Kennedy, 1950).

A rather closer examination of the feeding behaviour of hyperphagic rats shows that the onset of hyperphagia is immediate after operation; as they recover from the anaesthetic the rats will attempt to eat anything within reach, and the food intake in the first $24 \mathrm{~h}$ is as high as on any subsequent day. Initially the feeding is voracious, but the animal's behaviour becomes more apparently normal as it becomes fatter. Initially, again, the diurnal rhythm of feeding is completely upset, and the rat eats at irregular intervals throughout the day and night, apparently whenever its gastric distention is a little reduced, instead of eating chiefly in the morning and evening.

If hyperphagia is re-induced after a period of starvation, the original voracity reappears. This change in behaviour with the development of adiposity led us to investigate the effect on hyperphagic animals of diets that might reasonably be expected to reduce their food intake. Adolph (I947) had tried to do this in normal rats by giving diets containing inert substances, such as kaolin and cellulose, and had found that the rats simply increased their intake to compensate exactly for the diluent, so that they obtained the same intake of calories. We have been able to confirm that our normal rats would eat in this way 'for calories', but we found some striking differences between normal and hypothalamic obese rats. The behaviour of operated rats varied with the stage of obesity reached and can be summed up by saying that the fatter they got, the more discriminating they became. Immediately after operation they might eat more of a kaolin mixture than a normal rat, and continue to get fat on it, but later they would refuse it completely for many days, until they had lost a great deal of weight, when apparently their urge to eat increased sufficiently to compel acceptance of the diet. No adulteration of the diet ever caused an operated obese rat to become thinner than its control; as the weights of the rats approximated, their feeding became identical. This finding, that the fat rat can always be made to eat as well as the normal one after it has 
lost weight, we interpret as evidence that the primary urge to eat, which might be called hunger, is unaffected by the operation, which destroys only a centre involved in the inhibition of feeding, that is, a satiety centre. But the experiments emphasize another aspect of feeding behaviour, the discrimination against unpalatable diets. This is apparently of little importance in the intact rat, but is a major determinant of the amount the operated rat eats, and consequently of how fat it becomes. Discrimination can be illustrated without the use of bulky diets and has apparently nothing to do with distention of the gut. Miller, Bailey \& Stevenson (I950), subsequently to our work, have shown similar effects from adding quinine to the diet, or from using mechanical restraining devices to keep the animal from its food, and have found the same paradox, that a rat still hyperphagic enough to eat far more of its normal diet than an unoperated rat will nevertheless be much more easily deterred from feeding by whatever makes food more difficult to get or less attractive. We have suggested that the dominant hypothalamic satiety mechanism apparently obscures any effect of discrimination (Kennedy, I95 I). Damage to the hypothalamus both releases hunger from inhibition and allows discrimination to play a greater part in determining intake.

The fact that the intact rat is able from day to day to adjust its calorie intake to equal its calorie expenditure, even though its activity and the temperature of its environment may change greatly, might be taken to imply an integration of the constantly varying energy demand by the central nervous system and its translation somehow into hunger. Brobeck (1946) has, in fact, suggested this and has pointed out that all the variants concerned have their effect on heat production by the body. The hypothalamus is known to have thermosensitive areas and to play an important part in temperature regulation, so that it seems reasonable to suggest that food intake may be controlled as a part of an overall adjustment of body temperature. Though this might be an excellent mechanism for controlling the intake at a particular meal, it is a little hard to see how it could operate to keep the weight steady day by day, week by week, without some most unlikely intervention of 'energy memory'. And it would fail to explain the part played by the fat deposits in affecting food intake, so easily seen in the obese rat and implied in the normal rat by the constancy of fat content. Food can only affect the temperature regulation of the body if its energy is released as heat, and the fat, of course, has this energy intact. We have suggested the simpler hypothesis that the cells of the hypothalamus are chemosensitive rather than thermosensitive (Kennedy 1950, 1953). In this way one can explain not only the immediate influence of ingested food by its effect on the level of circulating metabolites in the blood, but also the delayed effect it could produce from the fat depots, which are in a state of constant exchange with blood metabolites. Such a theory is also compatible with the fact that, for example, a lactating rat may eat three times as much as a normal rat of similar weight. As two-thirds of the ingested food is removed through the mammary gland, it can have no further effect on blood levels, and it is not necessary to postulate any change in hypothalamic sensitivity during lactation.

If our hypothesis, that discrimination itself is unaffected by hypothalamic 
operation, but is merely emphasized by the weakening of the dominant calorimetric control, is correct, there ought to be little change in the type of food selected by fat rats. Both Brobeck and ourselves have found this to be so in simple selection tests. However, during the last year I had the opportunity with Dr. C. P. Richter in Baltimore of submitting obese rats to the elaborate self-selection regimes he has used in the study of specific appetites. We found that rats in early hyperhpagia would select successfully, but obese rats sometimes failed to select a diet and lost weight and, in spite of the presence of abundant food, might die of starvation. The interpretation of these experiments is difficult, but we believe it to be linked with the fact that after long periods on an unbalanced diet, or of actual starvation, the desire to eat may be lost. We found that giving the rats small quantities of a mixed diet for a few days restored their desire to eat, and they then selected an adequate diet and became fat again. The selection of a diet under these conditions is evidently a complex act, probably depending on other factors besides the specific appetite for the particular foods given.

Finally, where in the central nervous system does the hunger mechanism lie? Anand \& Brobeck (1952) have recently shown that very small bilateral lesions in the hypothalamus, rather further from the mid-line than the ones that cause increased food intake, abolish eating altogether and result in death from starvation. Unfortunately they have not excluded the possibility that this may be an irritative effect upon the connexions of the satiety mechanism. A rat can only tolerate complete starvation for a few days and might well die before the oedema after operation on the hypothalamus had settled down. It is, in fact, fairly common to get animals to refuse food for a few days, only to recover and subsequently to become fat. The only way to settle this question will be to feed such animals as Brobeck (1946) has described by tube, for a period long enough to allow healing, and then to note if their desire to eat has returned. Meanwhile, we see no reason to alter our view that the primitive urge to eat is probably mediated through some lower centre than the hypothalamus (Bruce \& Kennedy, 195I). It is, however, important to settle this point in view of its relevance to the aetiology of such conditions as anorexia nervosa.

Miller et al. (1950) first defined hunger in terms of the effort an animal would make to get food under adverse conditions and then concluded that hypothalamic damage reduced hunger because fat rats became lazy. On the other hand, as we have shown, the relative laziness or increased discrimination depends on the degree of obesity, and they can be made just as hungry as normal rats by removal of some of their fat. I believe that the complex system for controlling food intake can only be finally described by finding in the central nervous system those areas to which damage produces disturbance of feeding behaviour and then by careful definition of the departure in behaviour from that of the normal animal.

\section{REFERENCES}

Adolph, E. F. (1947). Amer. F. Physiol. I51, 16.

Anand, Bal K. \& Brobeck, J. R. (1952). Yale f. Biol. Med. 24, r23. 
Brobeck, J. R. (1946). Physiol. Rev. 26, 54r.

Brobeck, J. R., Tepperman, J. \& Long, C. N. H. (1943). Yale F. Biol. Med. 15, 83 I. Bruce, H. \& Kennedy, G. C. (195I). Proc. roy. Soc. B 38, 528.

Hetherington, A. W. \& Ranson, S. W. (1939). Proc. Soc. exp. Biol., N.Y., 4I, 465.

Kennedy, G. C. (1950). Proc. roy. Soc. B, 137, 535.

Kennedy, G. C. (1951). Proc. R. Soc. Med. 44, 899 .

Kennedy, G. C. (1953). Proc. roy. Soc. B, 140, 578 ,

Miller, N. E., Bailey, C. J. \& Stevenson, J. A. F. (1950). Science, 112, 256. 